\title{
Age at Menopause
}

National Cancer Institute

\section{Source}

National Cancer Institute. Age at Menopause. NCI Thesaurus. Code C106497.

The age at which permanent cessation of menses occurs. 